\title{
EL TERRITORIO VALENCIANO: SUS LIMITES Y DIVISIONES
}

910.1:353 (091). Valencia

por

Aurelio Guaita

Catedrático de la Universidad Autónoma de Madrid

En recuerdo de José Antonio García-Trevijano Fos y de nuestra convivencia en la Universitas valentina.

SUMARIO: I. EXTENSION, POBLACION Y ECONOMIA.-II. LOS. LIMITES DEL REINO DE VALENCIA.-III. TIERRAS VALENCIANAS QUE DEJARON DE SERLO.-IV. ADEMUZ: DOS VECES SEGREGADO Y RECOBRADO. EL BILINGUISMO.-V. INCREMENTOS TERRITORIALES.-VI. SUCESIVAS DIVISIONES DEL TERRITORIO VALENCIANO.-VII. LAS DIVISIONES SUPRA- O INFRAPROVINCIALES EN LA SEGUNDA MITAD DEL XIX.-VIII. VALENCIA, CAPITAL DE «REGIONES»ADMINISTRATIVAS ESPECIALES.-IX. APENDICE: «LA DENOMINACION QUE MEJOR CORRESPONDA A SU IDENTIDAD HISTORICA».

«... Castilla la Vieja se divide en ocho Provincias...; el Reino de León, en las de...; el de Valencia, en las de Valencia, Alicante y Castellón de la Plana...»: artículo 2..$^{\circ}$ del vigente Real Decreto de 30 de noviembre de 1833 sobre división provincial.

«El territorio de la Comunidad autónoma comprende el de los 
Municipios integrados en las Provincias de Alicante, Castellón y Valencia»: artículo $3 .^{\circ}$ del proyecto de Estatuto de Autonomía de Valencia, BOCG.CD, H-68, de 13 de octubre de 1981; y 15 de enero, 2 de febrero, 26 de abril y 12 de mayo de 1982; y BOCG.S, II-232, de 7 de mayo de 1982.

\section{EXTENSION, POBLACION Y ECONOMIA}

1. Actualmente, y ya desde 1851 , Valencia abarca 23.305 kilómemetros cuadrados (1), algo menos de la vigésima parte de la superficie total de España (504.750), en la que sólo supera a las Regiones insulares (Baleares, 5.014; Canarias, 7.273), a las Provincias Vascongadas (7.261) y a las Regiones uniprovinciales: Murcia (11.317), Asturias (10.565), Navarra (10.421), Madrid (7.995), Cantabria (5.289) y La Rioja (5.034).

Aun prescindiendo de los muy minúsculos (Andorra, Malta, Luxemburgo, etc.), excede también el territorio valenciano al de algunos Estados: por ejemplo, Chipre no cuenta más que con $9.250 \mathrm{ki}$ lómetros cuadrados; Israel tenía antes de la "guerra de los seis días» de 1967, 20.700 (un poco menos que la Provincia de Badajoz); El Salvador, 21.400. Y algo parecido puede decirse de algunos Estados norteamericanos: Rhode Island, 3.144 kilómetros cuadrados; Delaware, 5.328; Connecticut, 12.973; Hawai, 16.705; New Jersey, 20.295; Massachusetts, 21.386.

Pero ya superan a Valencia, v. gr., Guinea Ecuatorial $(28.000 \mathrm{ki}-$ lómetros cuadrados), y en Europa: Albania (28.748), Bélgica (30.500: un poco mayor que Galicia, un poco menor que Cataluña), Holanda (33.800), Suiza (41.293, ligeramente menor que Extremadura) o Dinamarca (43.000: Aragón, 47.669).

2. En el aspecto demográfico los datos son relativamente halagüeños: según el censo de 1 de marzo de 1981 (aprobado por Real Decreto de 27 de noviembre de 1981, BOE de 24 de diciembre) la población española de derecho era en aquella fecha de 37.682 .355 habitantes; y la valenciana, de 3.646 .778 , casi el 10 por 100 de la nacional; y conforme a esas cifras, las densidades por kilómetro cuadrado son, respectivamente, de 74 y 156 habitantes (2).

(1) El reparto provincial es como sigue: Valencia, $10.763 \mathrm{kms}$., el número $20 \mathrm{de}$ las Provincias españolas; Castellón, 6.679, el número 38; y Alicante, 5.863, el número 41 .

(2) - He aquí varios ejemplos de la población valenciana en siglos anteriores, aunque con diferencias y altibajos quizá más zigzagueantes y sorprendentes que fiables: 
La población está relativamente equilibrada, en cuanto no se produce el fenómeno de la macrocefalia que se advierte en otras Regiones: el porcentaje de la población de las capitales respecto de la de sus Provincias es como sigue: Alicante, el 21,40; Castellón, el 28,82, y Valencia, el 36,05, cifra esta última casi coincidente con el porcentaje del total de las capitales de Provincia respecto del conjunto nacional: el 36,45 .

Los Municipios de más de 10.000 habitantes son numerosos, setenta (550 en toda España) y en cambio, sólo las tres capitales provinciales y Elche pasan de 100.000; en cifras absolutas, la Provincia

a) «La població total del Regne de Valencia, al començar el segle XVII, era de devers 450.000 habitants»: REGLA I CAMPISTOL: Aproximació a la Història del País. Valencià, 3." ed., Valencia, 1975, 107.

b) El censo de 1712 contaba 63.702 familias, lo que para Henry KAMEN suponía unos 300.000 habitantes o pocos más: La Guerra de Sucesión en España, 1700-1715, Barcelona, 1974, 298-99; y para Domínguez OrTiz «a lo sumo podría llegarse a las 400.000 almas»: Sociedad y Estado en el siglo XVIII español, Barcelona, 1976, 265.

c) Al decir de Cavanilles, los habitantes de Valencia eran: en 1718, 255.080; en $1761,604.622$; en $1768,716.886$, y en $1787,783.084$ (pág. $X$ del vol. I); y al final de su obra dice que en 1794 «el número de vecinos es de 207.145, que calculados a 9 personas cada dos vecinos forman 932.150 almas»: Observaciones sobre la Historia Natural, Geografía, Agricultura, población y frutos del Reyno de Valencia, dos volúmenes, Madrid, 1795-97, II, 404; existe una excelente edición de José Manuel CASAS TORRES, Zaragoza, 1958; y una en facsímile de la primera, también en dos volúmenes, Valencia, 1972.

d) Según la «Instrucción que deberá observarse para la elección de diputados. de Cortes» de 1 de enero de 1810, artículo 10, España contaba 10.534 .985 almas; Valencia, 825.059. 1822:

e) Los datos que se leen en el decreto de división provincial de 27 de enero de

\begin{tabular}{|c|c|}
\hline & Habitantes \\
\hline 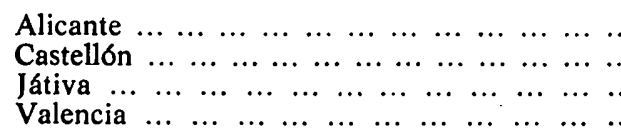 & $\begin{array}{l}255.170 \\
192.205 \\
164.795 \\
353.760\end{array}$ \\
\hline
\end{tabular}

f) Según el decreto de división provincial de 30 de noviembre de 1833 (Valencia vuelve a su territorio de fines del xviri):

\begin{tabular}{|c|c|}
\hline $\begin{array}{lllllllllllll}\text { Alicante } & \ldots & \ldots & \ldots & \ldots & \ldots & \ldots & \ldots & \ldots & \ldots & \ldots & \ldots & \ldots \\
\text { Castellon } & \ldots & \ldots & \ldots & \ldots & \ldots & \ldots & \ldots & \ldots & \ldots & \ldots & \ldots \\
\text { Valencia } & \ldots & \ldots & \ldots & \ldots & \ldots & \ldots & \ldots & \ldots & \ldots & \ldots & \ldots & \ldots\end{array}$ & $\begin{array}{l}368.961 \\
199.220 \\
388.961\end{array}$ \\
\hline & 957.142 \\
\hline
\end{tabular}

A partir de la primera mitad del xix, Valencia es territorialmente algo mayor: he aquí las cifras de los últimos cuatro censos:

\begin{tabular}{|c|c|c|c|c|}
\hline \multirow{3}{*}{$\begin{array}{lllllll}\text { Alicante } & \ldots & \ldots & \ldots & \ldots & \ldots & \ldots \\
\text { Castellon } & \ldots & \ldots & \ldots & \ldots & \ldots & \ldots \\
\text { Valencia } & \ldots & \ldots & \ldots & \ldots & \ldots & \ldots \\
& & & & & & \end{array}$} & 1960 & 1970 & 1975 & 1981 \\
\hline & $\begin{array}{r}718.213 \\
342.649 \\
1.438 .043\end{array}$ & $\begin{array}{r}922.027 \\
386.516 \\
1.769 .552\end{array}$ & $\begin{array}{r}1.051 .852 \\
410.119 \\
1.935 .343\end{array}$ & $\begin{array}{r}1.149 .181 \\
431.893 \\
2.065 .704\end{array}$ \\
\hline & 2.498 .905 & 3.078 .095 & 3.397 .314 & 3.646 .778 \\
\hline
\end{tabular}


de Valencia ocupa el tercer lugar entre todas las de España: 2.065.704 habitantes; la de Alicante, a pesar de su exiguo territorio, ha escalado ya al sexto lugar (en 1970 ocupaba el octavo), con 1.149.181; aunque algo mayor en superficie, la de Castellón queda ya muy lejos, en el puesto 30 (también ha ascendido: el 34 en 1970), con sus 431.893 habitantes. $Y$ algo análogo acontece en las capitales: Valencia ocupa el tercer lugar (744.748); Alicante, el decimoséptimo, entre todas las ciudades españolas (245.963: ha escalado un puesto respecto de 1970); y Castellón, el número 43, ha retrocedido tres puestos, aunque tiene ya 124.487 habitantes. Elche es mayor, 164.779, y ocupa el lugar 29 (el 32, en 1970). En fin: entre 50.000 y 100.000 habitantes existen sólo otros cinco Municipios: Alcoy, 66.396; Sagunto, 55.294; Elda, 53.128; Torrent, 51.762, y Orihuela, 50.084 habitantes (3).

El crecimiento de la población entre el censo de 31 de diciembre de 1970 y el de 1 de marzo de 1981 ha sido, en el conjunto de España, de 10,70 por 100; y en Valencia, de 18,48 por 100 ; además, ésta ha contribuido con el 15,62 por 100 al aumento de la población española en el último decenio.

3. De los 8.022 Municipios españoles, 534 son valencianos, esto es, casi el 15 por 100, distribuidos así: 262 en la Provincia de Valencia, que, en este orden, ocupa el puesto $7 ; 138$ en la de Alicante, lo que la sitúa en el número 27 de las Provincias españolas, y 134 en la de Castellón, con lo que ocupa el lugar número 28 (4). Esa proliferación lleva a que, en general, los términos municipales valencianos sean de reducida extensión: por término medio, no llegan a 44 kilómetros cuadrados, mientras que en el conjunto español pasan de 62; por supuesto, hay grandes desigualdades entre ellos: el mayor, $\mathrm{Re}-$ quena, con sus 815 kilómetros cuadrados, hace el número 18 en toda

(3) Hay también, por supuesto, bastantes pueblos muy pequeños y hasta diminutos: existen actualmente 18 Municipios cuya población no alcanza el centenar de habitantes, la mayor parte de ellos en la provincia de Castellón: ocho ni siquiera 1legan a 50 habitantes, y parece obligado citar el Peter Pan de los Municipios valencianos: Vallat, con 19 tan sólo: 10 hombres y 9 mujeres.

(4) Al decir de Macanaz, en 1713 había en Valencia 560 pueblos: Henry Kamen, 295; el cómputo de Cavanilles en 1794 era de 628: obra y lugar citados.

Claro que «pueblo» del siglo XviII no coincide siempre con Municipio del xx; aparte de que hubo en el xIX la incorporación a Valencia de nueve Municipios castellanos o murcianos, y en dicho siglo y en el actual la supresión de varias docenas de Municipos pequeños absorbidos por sus vecinos mayores.

Sobre las alteraciones municipales a lo largo de un siglo puede verse Amando Mrı́́N: «Modificaciones del mapa municipal de España a través de un siglo (1857-60 a 1960)", en Estudios Geográficos, 148-49, homenaje al autor (1977), 829-50. Pero en los años 60 y 70 de nuestro siglo siguió proliferando el fenómeno de reducción de Municipios, todavía con mayor intensidad. 
España; son también de considerable superficie, entre otros de menos importancia o significación: Orihuela, 560; Ayora, 442; Morella, 388; Villena, 344; Elche, 326; ... Liria, 235; ... Alicante, 201; ... Valencia, 135; Sagunto, 135; Alcoy, 131; ... Alcira, 111; ... Castellón de la Plana, 107; Segorbe, 107; ... Ademuz, 100; ... Ya con menos de 100 kilómetros cuadrados: Vinaroz, 96 ; ... Picasent, 85 ; ... Játiva, 77; ... Torrent, $69 ;$... Gandía, $62 ;. .$. Pero existen ocho que no llegan a un kilómetro de extensión, y es el menor de todos Lugar Nuevo de la Corona, pegado a la capital valenciana, reducido a diez hectáreas (5).

4. En el campo económico, Valencia es también una Región bastante equilibrada, tanto en relación con su demografía como por lo que se refiere a las cifras totales españolas. En efecto (fuente: Banco de Bilbao, estudio relativo a 1979; Bilbao, 1982):

En la producción neta, Alicante supuso el 2,94 por 100 del total nacional; Castellón, el 1,15; y Valencia, el 5,78: es decir, en conjunto, el 9,87 de España.

El porcentaje de la producción industrial en el producto interior neto fue: España, 34,4; Alicante, 38,9; Castellón, 40; y Valencia, 34,3.

Renta per cápita: España, 311.838; Alicante, 314.301 (puesto 17 entre las Provincias españolas: en 1977 ocupaba el 23); Castellón, 308.191 (número 18, como en 1977); la Provincia de Valencia, 331.430 (número 12: el 15 en 1977); y la renta regional, 323.287.

En la producción total, el lugar que ocuparon las tres Provincias valencianas entre todas las españolas fue: Valencia, el puesto número 3; Alicante, el 7; y Castellón, el 26 (el 25 en 1977).

En fin, la tasa de paro fue en Valencia 8,3, y en España, 9,5; y en el mismo año 1979, los porcentajes (cálculo propio, aproximado y redondeado) de población ocupada y empleos fueron:

\begin{tabular}{|c|c|c|c|c|}
\hline & $\begin{array}{l}\text { Agricultura } \\
\text { y pesca }\end{array}$ & Industria & Construccion & Servicios \\
\hline $\begin{array}{lllllll}\text { Ialencia } & \ldots & \ldots & \ldots & \ldots & \ldots & \ldots \\
\text { Talencian } & \ldots & \ldots & \ldots & \ldots & \ldots\end{array}$ & $\begin{array}{l}21 \\
17\end{array}$ & $\begin{array}{l}26 \\
31\end{array}$ & $\begin{array}{l}8 \\
8\end{array}$ & $\begin{array}{l}45 \\
44\end{array}$ \\
\hline
\end{tabular}

\section{LOS LIMITES DEL REINO DE VALENCIA}

1. Con los antecedentes de los pactos o tratados de Tudején o Tudillén (1151: Ramón Berenguer IV y Alfonso VII), Cazola (1179:

(5) La capital de Provincia de término más reducido es Cádiz, que no alcanza los $11 \mathrm{kms}$; ; las mayores, las dos extremeñas: Cáceres, con 1.768, y Badajoz, con 1.547. Pero aún las sobrepasa la murciana Lorca, que ostenta el récord nacional con sus $1.821 \mathrm{kms}$., casi tan grande como Guipúzcoa, que con sus $1.997 \mathrm{kms}$. es la menor de las Provincias españolas (la media de éstas, $10.100 \mathrm{kms}$.). 
Alfonso II de Aragón y Alfonso VIII de Castilla) y Almizra o Almirra (1244: Jaime I y el futuro Alfonso X), que delimitaban las futuras conquistas hacia el sur a costa de los Reinos musulmanes (6), al comienzo de los Furs valencianos (libro I, rúbrica I, furs 1 y 2), en su primitiva redacción latina, se trazaban esquemáticamente los límites del nuevo Reino de Valencia y los de las tierras directamente sometidas a la capital, su «término municipal». He aquí la transcripción literal de este breve texto fundacional del Reino valenciano, debido a Jacobus I Rex: «1. Vocamus et volumus ut Regnum Valentie appelletur, et sit a rivo de Uldecona usque ad terminum de Biar et a mari usque ad Alventosam et Almazaneram et ad Sanctam Crucem et ad finem terminorum de Requena, qui dividunt terminum versus Castellam (7).

2. Termini civitatis sunt: usque ad terminum de Murvedre [Morvedre, Murviedro: esto es, Sagunto], qui terminat cum Puzol; et usque ad terminum de Holocau, de Xiva, de Buynol [Bunyol], de Turris et usque ad Montem Serratum; et usque ad terminum de Algezira [Alcira] et de Culyera. Et ad littore maris sit et duret per centum miliaria intus mare» (8).

La redacción posterior, en lengua romance, terminada ya la conquista, conforme a lo pactado en Cazola y Almirra, pero todavía en pleno siglo XIII, es bastante más larga y detallada: «Aquests són los térmens del Regne de València: Del Canar de Ulldecona que és riba la mar, així com va Lo riu ensús e passa per la Cénia. E ix a Beni-

(6) El tratado de Cazola se limitó a señalar el puerto de Biar (hoy provincia de Alicante, cerca de las de Albacete y Valencia) como límite futuro entre Castilla y Aragón; el de Almirra (camp de Mirra) fue realmente una ejecución y concreción del anterior: la frontera entre las dos Coronas no se prolongaría desde Biar hacia el sur (como la vemos hoy entre las provincias de Alicante y Murcia), sino que doblaba hacia el este hasta llegar al mar algo al sur de Altea, que quedaba para el reino de Valencia; es decir, se "cristianizaba», respetaba o consagraba prácticamente la frontera preexistente entre los reinos musulmanes de Valencia y Murcia: se asignaba aquél al rey de Aragón (pero subsistió como reino, distinto al de Aragón) y al rey de Castilla el reino de Murcia (pero en lo sucesivo reino ya sólo nominal, englobado en el de Castilla a todos los efectos); Biar en el interior y Altea en el mar eran reino moro de Valencia y en lo sucesivo fueron reino cristiano de Valencia, según ya se ha dicho: también quedaban al norte de esa línea, por ejemplo, Castalla y Jijona.

El tratado de Tudillén o Tudején era o hubiese sido más favorable al rey aragonés, pues se le reconocía el derecho de conquista no sólo del reino de Valencia, sino también del de Murcia. Sin embargo, en parte y por otros procedimientos eso tuvo realidad a principios del xIv, cuando Jaime II prolongo hacia el sur el reino de Valencia, anexionando la zona oriental del reino castellano de Murcia, aproximadamente la mitad meridional de la actual provincia de Alicante, incluida su capital.

(7) En efecto, versus significa «hacia», no «contra» (adversus), aunque, especialmente en el lenguaje forense, lo empleen en este sentido los anglosajones; y ahora también algunos españoles.

(8) Cfr. Manuel Dualde: Fori Antiqui Valentiae, Madrid-Valencia, 1950-67; y Germà Colón y Arcadi García: Furs de Valencia, Barcelona, 1970, vol. I, 108-09. 
façà, en terme del Regne de València. E Morella ab sos térmens, així com parteix ab Monroig. $E$ ix al riu de les Truytes que és prop la Glesiola. E aixi com va a Arcedo e a Ledó, los quals són dins lo dit Regne. E així com va a la Mosquerola. E de la Mosquerola a Móra, e entenem Ruviols del dit Regne. E de Móra aixi com va a la Font de la Bavor. E aixi com va al riu d'Alventosa e ix a la Maçanera, però dellà el riu és d'Aragó, e del riu ençà és del Regne de València. E aixi com va a la serra de Javalambre. E de la serra de Javalambre aixi com ix a Castell Phabip e Ademuç, e aquests dos castells són del Regne de València. El d'Ademuç aixi com va al terme que parteix Ares e Sancta Creu. E d'alli aixi com ix al terme de Toixa e de $X e l v a$. E ix a Senarques e parteix terme ab Castella. E aixi com ix a Xerelli e a la serra de la Rua, e feneix a Cabriol. E al terme de Garamoxén e a la Font de la Figuera, e com ix a Burjaharon. E d'alli a Almizra e al port de Biar, que parteix terme ab Billena. E aixi com va a la serra de Biar entrò la Mola e entrò la mar, que parteix ab Bosot e ab Aygües» (9).

Pero la Valencia actual es bastante mayor que la encerrada en los límites que se acaban de transcribir, aunque también su territorio sufrió algunos recortes, y puesto que éstos fueron menores, vamos a comenzar por ellos.

\section{TIERRAS VALENCIANAS QUE DEJARON DE SERLO}

a) Como datos casi anecdóticos se puede recordar que según algunos autores: 1) «Yecla era de Castilla en tierras que fueron del mismo" Reino de Valencia (10); 2) que por la paz de Campillo o Agreda y la sentencia de Torrellas (8 de agosto de 1304) se acordó que, entre otras (v. infra V.a), pasara de la Corona de Castilla a la de Aragón la ciudad de Cartagena, pero fue cedida o devuelta poco después por Jaime II de Aragón, y Valencia a Fernando IV de Cas-

(9) Cfr. Manuel SANChis Guarner: Obra completa, I, Valencia, 1976, 89-90.

(10) Felipe MateU Y Llopis: Las monedas del Reino de Valencia, exposición sintética, Valencia, 1977, II, 21.

Agrega MATEU que «Favanella - Habanilla [Abanilla hoy] - había quedado de Murcia». Así es, pero hubo y hay otro Favanella, no Municipio, en tierras de Onil, que fue siempre Reino de Valencia: Robert I. BuRns: Jaume I y els valencians del segle XIII, Valencia, 1981, 61.

(11) Luis SuÁrez Fernández: Historia de España antigua y media, Madrid, 1976, III, 16-17; Antonio Uвieto ARTETA: Bernat Desclot, un historiador valenciano recuperado, Valencia, 1977, 7. 
tilla (11); y 3) que Arcos de las Salinas pertenecía también a Valencia en el año 1263 (12).

b) Como se ha visto en els Furs, inicialmente, Rubielos y Mosqueruela habian quedado para Valencia según la demarcación del Rey fundador del Reino, pero tres siglos después, en circunstancias y fecha exacta que desconozco, pasaron, o quizá fueron pasadas, al Reino de Aragón: "La raya divisoria entre Aragón y Valencia era el río Alventosa y así la estableció Jaime I, pero en el siglo xvi fue rectificada, y Rubielos y Mosqueruela, Ruviols y Mosquerola, que pertenecían al Reino valenciano, pasaron al aragonés» (13). Reciente todavía ese cambio de límites, pueden verse las dos líneas, por ejemplo, en los mapas del Reino de Valencia hechos en los siglos XvI y XVII en Amberes (Ortelius) y Amsterdam (Mercator y Blaew), en los que se lee: Limes nouus (vetus) inter Valentiam et Arragoniam.

c) Otro territorio valenciano perdido es el de Caudete (Caudet, Cabdet o Capdet en valenciano), villa que tuvo voto en las Cortes de 1645. Caudete era un enclave valenciano en Castilla, situación que se ve y lee con claridad en los mapas antes citados de los siglos XVI y xvII: «insula Valentiae in Castilliae pars», o «in Castellae Regnum", o "in Castellae regione»; pero en 1707, después de la batalla de Almansa, este territorio fue transferido a la "Provincia o Reino de Murcia y Partido de Villena» (14), hoy Provincia de Albacete. Por supuesto, en el mapa de Tomás LópEz no figura Caudete, y

(12) Robert I. BURNS, 185 y 217.

Arcos está situada en el sur de la provincia de Teruel, en la cuña que se dirige hacia la de Cuenca separando Ademuz del resto del territorio valenciano. Ignoro cuándo y por qué Arcos de las Salinas se incorporó a Aragón.

(13) MATEU y Llopis: Las monedas..., I, 4. Lo mismo puede leerse en SANchis Guarner: La Ciutat de València, sintesi d'Historia y de Geografía urbana, 2.: ed., Valencia, 1976, 85; y en Obra completa, citada, ibídem.

(14) Cfr. España dividida en provincias y subdividida en partidos, corregimientos, alcaldias mayores, gobiernos políticos y militares, asi realengos como de órdenes, abadengo y señorío, obra formada por las relaciones originales de los respectivos intendentes del Reyno, a quienes se pidieron de orden de S. M. por el Excmo. Sr. Conde de Floridablanca y su ministerio de Estado en 22 de marzo de 1785, con un nomenclátor o diccionario de todos los pueblos del Reino que compone la segunda parte, Madrid, MDCCLXXXIX, tomo I, 395 y 398.

"La vila aillada de Cabdet» había sido incorporada a Valencia en 1304 según SANCHIS GUARNER: Obra completa, 92: v. infra Va).

Precisamente uno de los asuntos tratados en las Cortes valencianas de 1645 se refería a la villa de Caudete. Fueron aquellas las últimas Cortes valencianas con producción legislativa, aunque el Archiduque Carlos las celebró, también en Valencia, en 1706. Antonio PÉREz MARTín (y Johannes-Michael Scholz): Legislación y jurisprudencia en la España del antiguo régimen, Valencia, 1978, 265.

Concuerda el texto con la generalidad de los autores al aludir a la pérdida de Caudete. Mateu Llopis: Las monedas..., II, 21; SANChis Guarner: Obra completa, 210; Emili Beüt y Belenguer: Geografía elemental del Regne de Valencia, 2.: edición, Valencia, 1978, 101. 
tampoco lo menciona Cavanilles, pues ambos publican sus trabajos a fines del xviri (15).

d) Durante el mismo siglo xviri perdió Valencia un pequeño territorio en forma de cuña hacia el sur, hoy Provincia de Teruel, y situado entre las de Castellón y Valencia; así se puede leer en el siempre exacto Cavanilles: "Los [montes] de la izquierda de la rambla [de la Pobleta] se hallan en el reyno de Aragón y término de Abejuela, que toma allí un jirón del de Valencia, entrando como dos leguas de norte a sur hasta cruzar la rambla. Perteneció aquel trozo o ángulo al reyno de Valencia por más de cuatrocientos años; pero a mediados del siglo actual [el XvIII] se decidió ser del reyno de Aragón» (16).

\section{ADEMUZ: DOS VECES SEGREGADO Y RECOBRADO. EL BILINGUISMO}

1. Desde el primer momento, se ha transcrito antes, "aquests dos castells [Castielfabib y Ademuz] són del Regne de València», pero

Ya queda dicho cuándo y por qué pasó Caudete del Reino de Valencia al de Murcia (por cierto, Caudete está al lado de Almansa). No es pues exacto que el cambio se produjera un siglo largo después, en la división provincial de 1833 básicamente vigente todavía hoy, como dice Carlos R. EGufa en la voz "Valencia», de la Gran Enciclopedia Rialp, GER, vol. XXIII, Madrid, 1975, 206.

Creo que es una confusión, pues leyendo la división de 1833 al trazar los límites entre Albacete-Murcia y Valencia-Alicante se ve que fueron respetados los preexistentes, sin introducir alteraciones territoriales en esta parte, lo que indica que Caudete ya no era de Valencia.

Con todo, se pueden transcribir estas líneas de Domínguez Ortiz, 264: "Caudete formaba un enclave valenciano en tierra murciana, lo que originaba grandes fricciones con los vecinos de Villena por cuestión de términos. También acusaban a los de Caudete de aprovechar su especial situación en la raya aduanera para contrabandear. Durante la Guerra de Sucesión los de Villena conquistaron Caudete y consiguieron que se les entregase como aldea. Recurrieron más tarde los de Caudete y en 1737 el Consejo de Castilla dio sentencia reintegrándola a su estado primitivo», es decir, de no sometimiento a Villena, pero no reintegrándola a Valencia.

Por cierto que según la prensa de 1 de diciembre de 1977, «el secretario accidental del Ayuntamiento de Caudete (Albacete), Andrés Boñon Martínez, separado de su cargo por propiciar la vuelta de esta localidad al Reino de Valencia, ha enviado un telegrama de protesta al Ministro del Interior, Rodolfo Martín Villa. El señor Boñón recogí hace unos meses firmas en la citada localidad para solicitar la abolición de las disposiciones posteriores a la Guerra de Sucesión, en las que el pueblo de Caudete, por su adhesión al archiduque Carlos, fue privado de sus privilegios y su pertenencia al Reino de Valencia, al vencer las tropas de Felipe V. En el telegrama manifiesta su protesta por su separación de la secretaría accidental que, según sus propias palabras, ha sido concertada por el gobernador con el diputado de UCD Ruiz Risueño».

(15) Es posible que la pérdida de Caudete para Valencia se debiese a Melchor de Macanaz - que era de Hellín, hoy provincia de Albacete también-, cuyo fervor antiforal, centralista y regalista es bien conocido; v. la nota 28: Macanaz y Játiva.

El pueblo en cuestión es distinto de Caudete de las Fuentes que se menciona infra, V.e) y que pasó de Cuenca a Valencia en 1851.

(16) Antonio Joseph Cavanilles, vol. II, libro III, núm. 11. 
en dos breves períodos, y en realidad quizá sólo en el papel, el llamado Rincón de Ademuz (siete Municipios) se asignó a Teruel: en la división prefectoral de José Bonaparte de 1810 (Teruel o Guadalaviar Alto, conforme a la manía fluvialista afrancesada del inspirador de esa división, Llorente), y en la división provincial del trienio liberal («los tres mal llamados años» para los absolutistas fernandinos) de 1822-23; pero, salvo esos dos episodios anecdóticos, Ademuz siempre perteneció al Reino de Valencia y, desde que se creó, a la Provincia de este nombre.

Por su extensión $\left(370 \mathrm{Km}^{2}\right.$ ) y población (3.866 habitantes en el censo de 1981) el Rincón de Ademuz es el mayor de los diez enclaves interprovinciales (17), situado entre las Provincias de Teruel y Cuenca; sorprendentemente, esa configuración «insular» no es conocida por ninguno de los mapas antes citados, y tampoco aparece en el de «Don Tomás López, Geógrafo de los Dominios de S. M. ... Madrid año de 1788" (tengo a la vista un ejemplar de la edición original). Pero Cavanilles sí percibió claramente que este territorio valenciano estaba aislado del resto del Reino, y dice así en el volumen II de su obra (dedica a Ademuz las págs. 89-100): "Por Rincón o tierras de Ademuz se entiende el recinto contiguo al Reyno de Valencia, cercado enteramente por los Reynos de Castilla y Aragón. No vemos en los mapas discontinuación alguna entre el Rincón y el Reyno de Valencia, y en todos ellos el término de Aras de Alpuente sigue sin interrupción hasta las tierras de Ademuz, sin duda porque los autores los hicieron por informes inexactos, y sin conocer el terreno que figuraban, naciendo de aquí y perpetuándose errores geográficos de mucho bulto. Procuraré rectificarlos según mis observaciones, hechas sobre el suelo que describo. [Subrayado mío; ¡cuántas cosas se describen 'a ojo y de memoria'! Cavanilles, que recorrió palmo a palmo todo el Reino, desde la primavera de 1791 'al fin de 1793', según nos dice en el prólogo, después de describir muy por menudo las tierras de Ademuz, sigue:] Por esta breve demarcación de límites se ve que las tierras de Ademuz quedan como cerradas enteramente por los Reynos de Aragón y de Castilla. Así es que cuando desde Aras se intenta penetrar en Ademuz, es preciso pisar antes parte de dichos Reynos: el de Aragón y término de Arcos, si se baja por La Losilla, aldea de muy pocos vecinos; y el

(17) Sobre enclaves y otras cuestiones conexas puede verse mi estudio sobre «La división provincial y sus modificaciones», $D A, 150$ (1972), 11-59, reproducido y ampliado luego en el libro División territorial y descentralización, Madrid, 1975, 31-94. 
de Castilla y término de Santa Cruz, si se toma a la izquierda en busca de este pueblo, que cae al poniente de Aras, y a dos leguas de distancia»; y añade: "Escolano ya dijo que 'con ser así que tienen Castielfabib y Ademuz cuatro leguas de diámetro, no se puede llegar a ellos del Reyno de Valencia, que no sea entrando por Santa Cruz, pueblo de Castilla, o por la hoja de La Carrasca en Aragón'».

2. Como otras tierras del interior valenciano, las del Rincón de Ademuz están en regresión, pues cuando hace diez años publiqué el artículo citado en la nota 17, su población era bastante mayor que la actual: se siente desatendida, marginada, olvidada, discriminada, y según noticias publicadas en la prensa el 26 de septiembre de 1981, los siete pueblos del enclave pensaban estudiar su posible trasvase a la Provincia de Teruel; algo parecido (sigo citando la misma fuente) puede suceder, y por lo mismo, en la zona de Ayora, donde «numerosos habitantes se definen como albaceteños y se desconoce totalmente el valenciano" (sobre Ayora, v. infra V.a); y en el Bajo Segura (prensa del 24 de febrero de 1982).

En efecto, tanto Ademuz como Ayora, y muchas otras comarcas de las tres Provincias (por ejemplo, por citar unas pocas poblaciones importantes, en la Provincia de Castellón, Segorbe; en la de Valencia, además de Ademuz y Ayora, Requena y Utiel; en la de Alicante, Elda, Orihuela y Villena), son de habla castellana, y en mi opinión, ahora más que nunca, por algunos organismos y escritores se les trata con despego... o simplemente no se les trata, como si no fuesen valencianos, cuando, evidentemente, son exactamente igual de valencianos que los demás (y puede que más que algunos de esos «demás»), pues lo mismo que, por ejemplo, Bélgica o Canadá, Valencia ha sido siempre un país bilingüe (18).

\section{INCREMENTOS TERRITORIALES}

a) El más importante tuvo lugar en fecha temprana, a poco más de medio siglo de que Don Jaime diera por enteramente concluida la conquista del Reino de Valencia, en 1245. En efecto, de

(18) Al tema de la lengua se dedica el artículo $70^{\circ}$ del proyecto de Estatuto de Valencia: en aplicación y desarrollo del artículo $32^{\circ}$ de la Constitución, el número 1 del citado artículo 7. declara que "Los dos idiomas oficiales de la Comunidad Autonoma son el valenciano y el castellano». Y esto último es y tiene que ser así, no sólo porque «El castellano es la lengua española oficial del Estado» y «Todos los españoles tienen el deber de conocerla y el derecho a usarla» (art. 3.1 Const.), sino también porque es la lengua materna o propia de una importante minoría de valencianos. 
resultas de la guerra entre Fernando IV de Castilla y Jaime II de Aragón, en 1304, éste vio aumentado el Reino de Valencia en dos zonas: el valle de Ayora (en el ángulo suroeste de la actual Provincia de Valencia) y, sobre todo, con la mitad meridional de la hoy Provincia alicantina, que incluyó, entre muchas poblaciones, Alicante, Elche, Santa Pola, Elda, Novelda, Orihuela y Guardamar, rebasando el río Segura y llegando desde entonces el vértice sur del Reino de Valencia prácticamente casi a la ribera norte del Mar Menor (19).

b) Con esas importantes adiciones (menos las pequeñas "partidas negativas» sufridas por Valencia en los siglos XVI y xvIII y ya recogidas en el capítulo III) llegó el Reino al siglo xIx y a la división provincial de 1833, pues las dos que precedieron a ésta (la de Bonaparte, en 1810, y la del trienio liberal, en 1822), aunque zarandearon inmisericordemente el mapa valenciano y el de toda España, fueron muy efímeras y encarnaron muy poco y a veces nada en la realidad (20), de modo que aunque ha de aludirse luego a dichas dos divisiones, que tanto añadían como restaban comarcas enteras a Valencia, aquí y ahora debe prescindirse de ellas: las tierras que segregaban de Valencia (se ha referido en el capítulo IV el caso de Ademuz porque ya era valenciano en la delimitación fronteriza hecha inicialmente por Jaime I) han quedado todas y siempre valencianas; las que agregaban, o se "perdieron» definitivamente, al no haber sido ratificadas por la división de 1833 o las posteriores modificaciones de ésta, o bien se debe a dichas modificaciones o división, y no a las de 1810 ó 1822 , el pertenecer actualmente a Valencia.

Como se sabe, la división de 30 de noviembre de 1833, debida fundamentalmente a Javier de Burgos, sigue básicamente vigente, pero como he estudiado en el libro citado ya en la nota 17, al menos diez Provincias vieron alterados sus límites entre 1836 y 1851, y precisa-

(19) Luis SuÁrez FERNÁNDEZ: Historia de España antigua y media, Madrid, 1976, III, 16-17; Ubieto ARTETA: La creación de la Corona de Aragón, Valencia, 1977, 20.

Como ya se ha dicho (III.a), Cartagena fue también asignada al Reino de Valencia en 1304, pero poco después renunció a ella Jaime II.

Tanto Sú́REZ como UBieto incluyen también Villena en la relación de poblaciones que hubo de ceder Castilla en la paz de Torrellas de 1304. Si fue así, indudablemente la perdió luego el Reino de Valencia (¿cuándo, en qué circunstancias?); desde luego, en el siglo Xviı pertenecía, como en el XIII, a Murcia..., pero véase en el texto el siguiente párrafo $c$ ).

(20) Por ejemplo, recuérdese que Alicante «fue una de las pocas ciudades españolas donde no consiguieron penetrar las fuerzas napoleónicas»: DoMfNGUEz ORTIZ, 270. 
mente la Provincia más favorecida con esos cambios de límites fue la de Valencia, que vio muy considerablemente aumentado su territorio en 1836, 1847 y 1851, a costa de Cuenca en este último año, y de Alicante los dos primeros; por su parte, Alicante fue levemente compensada con territorios de Albacete y Murcia; claro que los cambios de Alicante y Valencia fueron domésticos, interiores, pues no afectaban a las fronteras del viejo Reino.

c) Por Real Orden de 9 de septiembre de 1836 se dispuso lo siguiente: «Deseando S. M. la Reina Gobernadora que las rectificaciones de la actual división territorial que la conveniencia pública exige, se lleven a cabo desde luego, ha tenido a bien aprobar respecto de la Provincia de Alicante [y las de Valencia, Albacete y Murcia] las disposiciones siguientes, propuestas por la comisión mixta encargada de la rectificación de límites de las provincias y arreglo de partidos judiciales: $1 .^{\text {a }}$, que los tres partidos de Onteniente, Albaida y Gandía se separen de dicha provincia y se agreguen a la de Valencia [el pueblo de Miraflor, hasta entonces del Partido de Gandía, siguió y sigue en la Provincia de Alicante, Partido de Denia]; 2. ${ }^{2}$, que se forme un nuevo partido en la primera [la Provincia de Alicante], cuya capital sea Villena, perteneciente ahora al partido de Almansa, en la provincia de Albacete, que comprenda a Sax, del partido de Yecla, en Murcia; Biar, del de Jijona, y Benejama, del de Alcoy, en la provincia de Alicante...»; las demás disposiciones de esta Real Orden se refieren a modificaciones internas en los Partidos de la Provincia de Alicante. En virtud de ella, por consiguiente, pasaron de Alicante a Valencia los Partidos de Onteniente, Albaida y Gandía (salvo Miraflor), y pasaron a Alicante: desde Albacete, Villena (21), y desde Murcia, Sax.

d) Un nuevo cambio, en la misma «dirección» y complementario del anterior, afectó también a las Provincias de Alicante y Valencia, según Orden del Ministerio de la Gobernación comunicada en 21 de

(21) En el libro de F. Almela y Vives: Valencia y su Reino, Valencia, 1965, páginas 224-25, hay algunas inexactitudes en esta materia: como se ve en el texto, Villena pertenecía a la provincia de Albacete, no a la de Murcia; y el traspaso de los pueblos de la zona norte de Alicante al sur de Valencia tuvo lugar en 1847, pero sólo en pequeña parte (véase a continuación $d$ ), pues los más de ellos habian pasado a Valencia ya en 1836, como se dice en el texto. Tampoco pasó a ésta desde Cuenca todo el partido de Requena, sino sólo su parte situada al este del Cabriel (véase infra e). 
noviembre de 1847 (22): «He dado cuenta a la Reina (Q.D.G.) del expediente promovido en este ministerio a instancia de los ayuntamientos de Oliva, Potríes, Fuente-Encarroz, Villalonga y otros pueblos pertenecientes al partido judicial de Pego en esa provincia [la de Alicante, a cuyo 'gefe político' - Gobernador civil- se comunicaba esta orden] en solicitud de que se les segregue de la misma, e incorpore en la de Valencia como más inmediata y de más fácil y segura comunicación. Enterada S. M. y de conformidad con lo informado en el asunto por la Sala de gobierno de la Audiencia del Territorio, se ha servido resolver que, sin perjuicio de hacer con mayor copia de datos la conveniente rectificación de límites entre esa provincia y la de Valencia, queden desde luego incorporados a ésta y partido de Gandia, los pueblos de Oliva, Potries, Fuente-Encarroz, Villalonga y Rafelcofer, y que los de Terrateig, Montichelvo, Benicolet, Luchente y Pinet, del partido de Gandía, se agreguen al de Albaida como propone la misma Sala».

La Orden del Ministerio de Hacienda de 10 de agosto de 1843 es «relativa a la habilitación del puerto de Denia en la provincia de Valencia», pero seguramente se refería a Provincia marítima, o bien, en otro caso, fue un error, pues Denia siempre fue, como hoy, Provincia de Alicante, aunque ya junto a la de Valencia después de las. alteraciones referidas de 1836 y 1847.

e) Y una tercera agregación, la más extensa, benefició a la Provincia de Valencia, y fue determinada por la Real Orden de 25 de junio de 1851, ahora «a costa» de la Provincia de Cuenca y, como los de 1836 y 1847, "en favor» de Valencia: "La Reina se ha enterado del expediente instruido sobre la conveniencia de trasladar a la provincia de Valencia la ciudad de Requena y demás pueblos que comprende su partido judicial y se hallan situados al otro lado del río Cabriel, perteneciente en la actualidad a Cuenca, quedando en lo sucesivo el mencionado río de límite que divida las dos provincias. En su vista, y atendidas las razones que así lo aconsejan, $S$. $M$. se ha servido resolver que la ciudad de Requena y las villas de Utiel, Caudete [de las Fuentes], Venta del Moro, Camporrobles, Fuenterrobles y Villargordo del Cabriel se incorporen y pertenezcan en adelante a la provincia de Valencia, fijándose por límite divisorio de ésta y la

(22) Publicada por el Gobernador de la Provincia de Valencia, José Soler, con fecha 5 de diciembre de 1847, en el Boletín Oficial de Valencia, núm. 147, correspondiente al 8 de los mismos mes y año. Agradezco a don Rafael Rodríguez-Moñino, Secretario general de la Excma. Diputación Provincial de Valencia, haberme facilitado estos datos. 
de Cuenca en aquel territorio el río Cabriel, y que los demás pueblos comprendidos hasta aquí en el partido judicial de Requena, que no se trasladan a la provincia de Valencia, queden incorporados en el partido judicial de Motilla del Palancar. De real orden ... Firmado, Beltrán de Lis».

f) En resumen: de las seis disposiciones sobre alteraciones provinciales que he podido documentar con certeza, las tres más importantes, con mucho, así en número de Municipios como demográfica y territorialmente, son las que se acaba de reseñar y que supusieron la incorporación a Valencia de los Municipios de Sax (antes, Murcia) y Villena (antes, Albacete) a la Provincia de Alicante, y la de Requena, Utiel, Caudete de las Fuentes, Venta del Moro, Camporrobles, Fuenterrobles y Villagordo del Cabriel que, todos siete, de la Provincia de Cuenca pasaron a la de Valencia.

Fue además ésta la que abrió en 1836 y cerró en 1851 la etapa de las rectificaciones. La Orden del Regente del Reino (Espartero) de 17 de agosto de 1841 dispuso que, estando ya reunidos en el Ministerio de la Gobernación los datos necesarios para llevar a cabo el proyecto de ley sobre división territorial, se suspendiera «toda variación, así en las capitalidades como en las demarcaciones civiles, judiciales y administrativas». Pero sí hubo otras variaciones, al menos cinco (tres de ellas ajenas a Valencia), aunque no después de 1851, pues como la Orden del Regente que se acaba de citar y, por los mismos motivos (preparar un expediente general comprensivo de todas las rectificaciones pedidas o proyectadas para decidirlo todo en la futura ley de división territorial), la Real Orden de 1 de marzo de 1856, de Escosura, suspendió la tramitación de los expedientes iniciados sobre este extremo. Y fuese o no consecuencia de esa orden, es lo cierto que no ha habido más alteraciones en la línea divisoria de las Provincias o yo no las conozco (23).

(23) Me refiero a cambios directos, que responden a la voluntad deliberada de alterar los límites provinciales, los que desde la Ley provincial de 25 de septiembre de 1863 requieren una ley; lo mismo el artículo 10 de la Constitución de 9 de diciembre de 1931, el 205 LRL y el 141.1 de la Constitución Española vigente; por cierto, en ésta, ley orgánica.

Pero sin necesidad de ley los límites pueden ser modificados «como consecuencia de la alteración de términos municipales limítrofes y pertenecientes a distinta jurisdicción provincial» (art. 205.1 LRL): tal fue lo acontecido con San Quirce de Riopisuerga, provincia de Burgos hasta 1973, año en que por Decreto de 1 de febrero se incorporó al Municipio de Alar del Rey, de la provincia de Palencia. Y como si fuese una compensación o permuta, por Real Decreto de 29 de septiembre de 1978 se aprobó la incorporación de San Llorente de la Vega, hasta entonces de la provincia de Palencia, al Municipio burgalés de Melgar de Fernamental. 


\section{SUCESIVAS DIVISIONES DEL TERRITORIO VALENCIANO}

a) Inicialmente se distinguían tres zonas o gobernaciones: "dellà Uixó» (más allá de Uixó o Uxó: Castelló de la Plana, antes. Castelló de Burriana), "dellà Xúquer» (Júcar: Xátixa) y la parte o gobernación central (Valencia), que era «deçà Uixó» o "deçà Xúquer», según a la que se contraponía. A partir de 1305 esas tres gobernaciones integraban la "governació major» (Castellón y Játiva eran como subgobernaciones dependientes de la de Valencia), al agregarse otra gobernación mucho más pequeña "dellà Xixona", con capital en Oriola u Orihuela (24), de modo que podría decirse, con mentalidad y categorías actuales, que venían a ser a manera de cuatro Provincias: Valencia reunía en sí la capitalidad del Reino ("cap y casal del Regne»), la de la gobernación mayor, la de la zona central de ésta y, en fin, la de lo que hoy llamaríamos su término municipal, inicialmente desde Morvedre (Sagunto) (25) a Cullera, como ya hemos visto decía la ley II de la rúbrica I del libro I dels. Furs (26).

b) En el siglo xviri, aun después de 1707 (25 de abril, batalla de Almansa; 29 de junio, Real Decreto de abolición de los Fueros valencianos y aragoneses), siguió hablándose de Reino de Valencia, pera

(24) ReGLג, 84; Germà Colón y Arcadi García: Furs..., 169.

Al poco tiempo de la conquista, todavía en vida de Jaime $I$, concretamente en 1270 , se dividía el territorio, del Cenia o Senia a Biar, en 41 distritos o zonas a efectos recaudatorios de la población mudéjar, extraordinariamente importante sobre todo en el sur (generalmente superior o más numerosa que la cristiana): 12 zonas al norte del Júcar y 29 al sur de este río: BuRNs, 114.

(25) Las gloriosas ruinas de Sagunto («muros viejos», al parecer) hicieron que el topónimo fuera sustituido al menos ya desde la Alta Edad Media por Morvedre o Molvedre, Murviedro en castellano, pero la antigua protegida de Roma recuperó su primitiva denominación, y a sus instancias, en 1868, y fue así: «En vista de la instancia del Ayuntamiento de Murviedro solicitando se sustituya el nombre de aquella villa por el de Sagunto, sobre cuyas ruinas fue edificada su población, y considerando que el objeto de dicha petición es el de perpetuar un hecho heroico que ha sido siempre objeto de admiración para los amantes de las glorias patrias, y que para que permaneciese vivo se dio el nombre de Sagunto a uno de los regimientos de nuestro Ejército, siendo más natural que lo lleve la población misma, como miembro del Gobierno provisional de la Nación y ministro de la Gobernación, he acordado acceder a la expresada solicitud, disponiendo en su consecuencia que la villa de Murviedro se denomine en lo sucesivo de Sagunto.-Madrid, 1.

(26) Según Germà CoLón y Arcadi García, en el siglo xvir, del brazo real tenían asiento en les Corts las ciudades de Valencia (cinco votos o síndicos), Játiva, Alicante y Orihuela; y las villas del patrimonio real de Morella, Alcira, Castellón, Villarreal, Onteniente, Alcoy, Burriana, Cullera, Liria, Biar, Bocairente, Alpuente, Peñíscola, Penáguila, Jérica, Jijona, Villajoyosa, Caudete, Corbera, La Yesa, Ollería, Carcagente, Benigánim, Villafamés, Onda y Callosa: cuatro ciudades y veintiséis villas. Furs..., 11.

Los señoríos de la nobleza a principios del Xvir, según el censo de 1609 y según Escolano (no totalmente coincidentes), pueden verse en Antonio Gil Olcina: La propiedad señorial en tierras valencianas, Valencia, 1979, 193-210. 
las dos o cuatro gobernaciones mencionadas en el párrafo anterior fueron sustituidas por trece (el mismo número que en Aragón y Cataluña, no sé si por casualidad o de intento) que, de Norte a Sur y del interior hasta el Mediterráneo, eran las siguientes: Morella (la segunda en extensión), Peñíscola, Castellón (muy pequeña), Valencia (la mayor: desde Aragón y Castilla, incluido el Rincón de Ademuz, hasta el mar), Alcira, Cofrentes (la única en la que no había ninguna población de realengo) (27), Montesa, San Felipe (28), De-

(27) KAMEN, 296 y 437.

Debe advertirse que las dos gobernaciones o partidos de menor población, Cofrentes y Montesa, funcionaban ordinariamente como agregadas a San Felipe, como si fuesen dos anejos de ésta: «están sujetas al bastón» de la gobernación de San Felipe, dice el mapa de Tomás LOPEZ.

Había además las tres «villas eximidas» o pías fundaciones del Cardenal Belluga: Nuestra Señora de los Dolores, San Fulgencio y San Felipe Neri, distinta, claro, de la San Felipe o Játiva, mencionada en el párrafo anterior de esta nota. España dividi$d a . . ., 549$, las menciona al terminar la gobernación de Orihuela.

(28) En la Guerra de Sucesión (para Valencia, 1705-09) no todas las poblaciones se inclinaron por el archiduque Carlos: por ejemplo, terminada la contienda Felipe V honró y premí́ la fidelidad de Morella, Peñíscola, Nules, Almenara, Benasal, Murviedro, Puzol, Cheste, Siete Aguas, Carcagente, Fuente de la Higuera, Jávea, Biar, Castalla, Onil, Ibi, Tibi, Petrel, Bañeres, Elda, Monóvar, Jijona, ... «y la lista de las ciudades fieles no acaban ciertamente aquí»: KAMEN, 326-28.

Pero también es cierto que la mayor parte del Reino, como Aragón, Cataluña y Mallorca, se mostró partidario del pretendiente austríaco: no pocas ciudades opusieron una tenaz resistencia a las tropas realistas, por ejemplo, Quart, junto a Valencia, y, en el sur, Alcoy, Denia, Elche, Orihuela, Alicante (la última ciudad en capitular); pero en su lucha contra Felipe de Anjou destacó heroica y encarnizadamente Játiva: cuando después de la batalla de Almansa logró expugnarla el duque de Berwick, nacido inglés pero al servicio del Rey, éste la castigo, sancionó su destrucción e incendio y además le suprimió el nombre, la antigua Saitabi, rebautizándola con el suyo mismo: San Felipe.

Según escribió Amando Melón, el nombre de San Felipe «fue impuesto por el furibundo regalista Macanaz». "De la división de Floridablanca a la de 1833 ", reproducido en el núm. 148-49 (1977) de Estudios Geográficos, homenaje al autor, II, 628.

Pero en un acto de auténtica reparación y justicia, las Cortes de Cádiz, por su decreto XCIX, de 28 de septiembre de 1811, establecieron: "Las Cortes generales y extraordinarias, atendiendo a los méritos y servicios de la ciudad de Xátiva en el Reyno de Valencia, que fue despojada de este nombre por el Sr. Rey D. Felipe V, queriendo además dar un testimonio de benevolencia a sus leales habitantes, decretan: Que se restituya a la misma ciudad su antiguo nombre de Xátiva, y no se la repute en adelante por colonia o población nueva.-Tendrálo entendido el Consejo de Regencia para que disponga su cumplimiento, y lo haga imprimir y publicar.-Dado en Cádiz a 28 de septiembre de 1811.-Bernardo, Obispo de Mallorca, Presidente.-Antonio Oliveros, Diputado secretario.-Juan de Balle, Diputado secretario.-Al Consejo de Regencia.-Reg. fol. 155».

En 1814, Fernando VII anuló toda la obra legislativa de Cádiz, con lo que Játiva volvió a ser San Felipe, pero de nuevo las Cortes, ahora por su Decreto de 25 de septiembre de 1837, devolvieron su nombre a la ilustre ciudad patria de los dos papas españoles: «Doña Isabel II, por la gracia de Dios y la Constitución de la Monarquía española, REINA de las Españas, y en su nombre Doña María Cristina de Borbón, Reina Regente y Gobernadora del Reino, a todos los que las presentes vieren y entendieren, sabed: Que las Cortes han decretado y Nos sancionado lo siguiente: Las Cortes, en uso de sus facultades, han decretado: Se restablece el Decreto de las anteriores de 28 de septiembre de 1811, en que se restituye a la ciudad de San Felipe su antiguo 
nia, Jijona (29), Alcoy, Alicante y Orihuela (30).

Las ciudades, villas y lugares que comprendía cada una de esas tan desiguales gobernaciones o partidos (en extensión, en habitantes, en riqueza, en capitalidades) figuran con no pocos datos interesantes en La España dividida... citada en la nota 14; también, por ejemplo, en el asimismo mencionado mapa de don Tomás LóPEZ, en el que se ve que la gobernación de Castellón poseía un pequeño enclave (Villanueva de la Reina) junto a Aragón; y que, por su parte, la de Jijona contaba con dos: el minúsculo de Salinas, junto a Murcia, y el más extenso e importante de Elche; en cambio, sorprendentemente, el mapa de LOPEZ, como ya se ha dicho, no advirtió la naturaleza de enclave del Rincón de Ademuz (gobernación de Valencia), a pesar de su extensión y de encontrarse por completo aislado respecto del resto del territorio valenciano, rodeado enteramente por Aragón y Castilla.

c) La división en trece gobernaciones de que se acaba de hablar

nombre de Játiva, y se manda que no sea reputada por colonia o población nueva. Palacio de las Cortes, 17 de septiembre de 1837.- Juan de Muguiro, Vicepresidente.José Feliu y Miralles, Diputado secretario.-Cristóbal de Pascual, Diputado secretario. Por tanto, mandamos a todos los Tribunales, Justicias, Gefes, Gobernadores y demás autoridades, así civiles como militares y eclesiásticas, de cualquier clase y dignidad que sean, que guarden y hagan guardar, cumplir y ejecutar el presente Decreto en todas sus partes. Tendréislo entendido para su cumplimiento, y dispondréis se imprima, publique y circule.-Está rubricado de la Real mano.-En Palacio a 25 de septiembre de 1837.-A D. Diego González Alonso».

Se comprende que los setabenses no sientan especial devoción por Felipe V.

(29) Aunque en las págs. 298 y 361 de su excelente libro KAMEN cita como una de las gobernaciones a Elche, ésta pertenecía, si bien separada o aislada, a Jijona, como por cierto se ve en la pág. 439.

(30) Después de Valencia, y a gran distancia de ella, las gobernaciones más pobladas eran Morella, San Felipe y Denia.

No coincidían sus capitales o sedes con las que tenían rango de ciudad, que eran estas nueve: Valencia, Peñíscola, Segorbe, Játiva, Gandía, Denia, Jijona, Alicante y Orihuela. Ahora se concede por el Gobierno (por ejemplo, por Real Decreto de 14 de octubre de 1978, BOE de 8 de noviembre, a Silla; y, con anterioridad, a Torrent, también en Valencia), pero no tiene ningún contenido jurídico, es una palabra: para la legislación actual no hay más que Municipios... o pueblos menores que no llegan a serlo.

Salvo unas pocas excepciones, por ejemplo, Segorbe, Liria, Gandia, Denia o Elche, las poblaciones más importantes eran de realengo (no llegaban éstas a 80 en todo el Reino), pero la inmensa mayoría de los pueblos valencianos eran de señorío secular - eclesiástico ya antes del xviri, y en buena medida pertenecían a la nobleza castellana. De la extremada opresión a que por lo general sometían los nobles a sus vasallos se hace eco reiteradamente y con incontenida irritación Cavanilles, como recuerda muy oportunamente DomínGUEZ ORTIz, 267-70.

En KAMEN, 433-39, puede verse una relación completa de las ciudades, villas y lugares de realengo a mediados del siglo xvili, y una amplia y seleccionada lista de los pueblos de señorio que «debe bastar para ilustrar el poder preponderante de la nobleza». Para finales del mismo siglo, véase La España dividida..., pássim. 
duró prácticamente hasta la vigente de 1883 , pero antes de ésta, y ya en el siglo xix, hubo dos pequeños paréntesis.

Se refiere, el primero, a la división decretada por José Bonaparte el 17 de abril de 1810: de las 38 prefecturas con que contaba la Península, dos eran las de Valencia y Alicante, pues a última hora se desistió de llamarlas departamentos y con apelativos geográficos como había propuesto Llorente y se había hecho en Francia: la de Valencia iba a ser Guadalaviar Bajo, y la de Alicante, Cabo de la Nao. Como todas las demás prefecturas (salvo la de Murcia, la mayor, que tuvo cuatro, y las de Ciudad Real, Cuenca, Madrid, la más pequeña, y Teruel, que sólo tenían dos) se dividían en tres subprefecturas, una de las cuales era la de la propia capital de prefectura: las otras dos de Valencia eran Segorbe y Castellón de la Plana; y las otras dos de Alicante, Játiva y Denia (31).

(31) Amando MelóN: «El mapa prefectural de España (1810)», en Estudios Geográficos, 46 (1952), 5-72.

Las divisiones de 1822 y 1833 son muy conocidas y pueden verse, por ejemplo, en mi División territorial..., 97 y ss.

Esta de 1810 la publicó Amando Melón en su trabajo que se acaba de citar, del que reproduzco seguidamente la descripción de los límites de las provincias de Alicante y Valencia:

ALICANTE: "Confina al Oeste. Con la Prefectura de Murcia: sus límites la línea que parte del puente de Alcalá del Río (sobre el Xúcar); se dirige hacia el Sur; pasa al E. de S. Lorenzo, Casas de Valiente, de Bete, Higueruela, Corralrubio, Piñuela, Fuente el Espino (en el camino de Jumilla a Yecla), Garrobo, Avanilla y Santomera, que pertenecen a la Prefectura de Murcia; dexando al E., y por consiguiente a la Prefectura de Alicante, Latoz, Cercelén, Bonete, Montealegre, Yecla, Quebrada (que se halla en las sierras del Carache y de Salinas) y Orihuela; luego encuentra el río $\mathrm{Se}$ gura, entre Segura y Santomera, y sigue su dirección hasta su embocadura en el mar.

Al Norte. Con las Prefecturas de Cuenca y de Valencia: de la primera se halla separada por la porción del río Xúcar comprehendida entre el puente de Alcalá del Río, y el punto donde desemboca en dicho río el Cabriel, y de la segunda por el mismo río Xúcar desde el punto en que se une con él el río Cabriel hasta su desembocadura en el mar.

Al Este y Sueste. Con el Mediterráneo».

VALENCIA: "Confina al Sur. Con la Prefectura de Alicante: límites el río Xúcar desde el punto donde se une con el Cabriel hasta su desembocadura en el mar.

Al Oeste. Con la Prefectura de Cuenca, de la qual se halla separada por una línea que parte desde el río Guadalaviar, media legua más al S. de Santa Cruz; se dirige hacia el S.; pasa al E. de Talayuelas, de Aliaguilla, de Fuentes Robres y de Villalgordo, que pertenecen a la prefectura de Cuenca; y al $\mathrm{O}$. de la Gesa, Ares, Sinarcas, Utiel y Caudete, que pertenecen a la de Valencia; encuentra el río Cabriel cerca y al $O$. de Caudete, y sigue su dirección hasta que desemboca en el Xúcar.

Al Norueste. Con la Prefectura de Teruel: sus límites la línea que parte de un punto que se halla un poco más al $S$. de Vistabella, entre este lugar, los de Villahermosa y Lucena; pasa al N. de Villahermosa, de Cortes de Arenoso y de San Agustín, entre las Alcotas y el Toro, entre Avejuela y Layesa; sigue hacia el O., y pasa entre las Aras de Alpuente y el Collado, y se termina en el Guadalaviar media legua más al S. de Santa Cruz.

Al Norte. Con la Prefectura de Tarragona: la línea que las separa parte del mismo punto que la anterior, un poco al $\mathrm{S}$. de Vistabella, entre este lugar y los de Villa- 
El Júcar era la divisoria entre ambas prefecturas, con las que, como en el resto de España, se hizo tabla rasa de la historia: se añadían a alguna de aquellas dos lugares o pueblos que no habían sido. nunca valencianos: por ejemplo, Requena, Utiel y Caudete (32), o. Almansa, Yecla y Villena (33). En cambio, se segregaban lugares, villas y comarcas enteras que siempre habían sido Reino de Valencia, por ejemplo, todo el norte: Morella, el Maestrazgo — contra lo. que suele creerse, nunca perteneció a éste aquella ciudad-, etc.; Vistabella y Alcalá de Chivert ya se asignaban a la prefectura de Tarragona, en la que, por de contado, entraban también San Mateo, Benicarló, Peñíscola, Vinaroz, etc.; Ademuz se asignaba a Teruel (Guadalaviar Alto); Cofrentes (la confluencia -como Koblenz o Coblenza- del Júcar y el Cabriel) entraba en Cuenca (Júcar Alto); y las tierras al sur del Segura fueron para Murcia (Segura).

d) La primera división provincial moderna española (no lo era la de Bonaparte, aunque sí de España) fue la acordada por las Cortes del trienio liberal mediante su Decreto LIX, de 27 de enero de 1822, pero estuvo en vigor tan sólo hasta 1 de octubre de 1823 , en que Fernando VII declaró nulo y sin valor cuanto habían hecho las. Cortes.

Una nueva división que sustituyera a la arcaica heredada del XviII ya había sido anunciada y prometida por el artículo 11 de la Constitución de Cádiz: "Se hará una división más conveniente del territorio español por una ley constitucional, luego que las circunstancias políticas de la Nación lo permitan». Y a esto respondía la división de 1822 , si bien ya queda dicho que «las circunstancias políticas de la Nación» no eran todavía favorables a lo que sin duda se juzgaba una modificación revolucionaria.

Como en la división prefectural francesa, Valencia fue estirada y comprimida con consciente menosprecio de la historia. Ya en 1812 un diputado, Pelegrín, había proclamado en las Cortes que "había llegado el caso de olvidar los nombres de los reinos y señoríos que componen la Monarquía española, y de que no se volviesen a oir las denominaciones de catalanes, aragoneses, castellanos, etc., adoptan-

hermosa y Lucena; y dirigiéndose hacia el E., pasa al S. de Alcalá de Chisvert, y va a terminarse en las orillas del mar en torre y cabo del Cuervo, entre Oropesa y Peñíscola.

Al Este. Con el Mediterráneo».

(32) Lo son desde 1851: cfr. supra V.e).

(33) Esta última lo es desde 1936: cfr. la nota 19 y V.c). 
do otra aun para la denominación de las provincias, o al menos dividiendo el territorio sin consideración a sus antiguos limites» (34).

Se volvían a incluir en Valencia, por ejemplo, Requena y Villena; y por el noroeste, novedad, una pequeña franja (Mosqueruela, Iglesuela, Cantavieja) que venía a recordar la que perdió Valencia en el siglo Xvi, según se ha dicho en el segundo párrafo del capítulo III; de nuevo se segregaba Ademuz (para Teruel) y ahora además Orihuela (para Murcia). Con todo, es justo reconocer que en esta división de 1822 las fronteras valencianas eran bastante más parecidas a las del antiguo Reino que las establecidas por Bonaparte.

Otra diferencia importante respecto de la división en dos prefecturas en 1810 y en tres provincias en 1833, y que recuerda la tetradivisión de la época foral: el nuevo territorio valenciano (no coincidía con el histórico: había diferencias en más y en menos, ya queda dicho) se dividía en cuatro Provincias: Castellón, Valencia, Játiva y Alicante.

Castellón era algo menor que en la actualidad, pues Segorbe y toda la cuenca valenciana del Palancia se asignaba a la Provincia de Valencia; a ésta la separaba de la de Játiva el Júcar; por último, los lindes entre Játiva y Alicante trazaban una línea algo más al sur de lo que hizo luego Javier de Burgos para separar Alicante de Valencia pues, por ejemplo, se incluían en Játiva: Onteniente, Albaida y Gandía (35).

Mayor fortuna que la efímera división de 1822 ha conocido la de 30 de noviembre de 1833 que, asediada por múltiples contradictores, ha resistido impávida siglo y medio; y en mi opinión se merecía esa mejor fortuna pues, sin parecerme perfecta, y sin duda sin serlo, es bastante defendible; pero eso ya lo razoné in extenso en División territorial y descentralización.

Esta división en tres Provincias que los niños aprenden en la escuela respetó los limites de Valencia tal y como se encontraban desde mediados del XVIII -incluidos Ademuz (36), Orihuela, etc.-. si bien luego se agregaron otros territorios en 1836 y 1851, como ya se ha expuesto en el capítulo V: la zona de Requena-Utiel y otros cinco Municipios, a Valencia; y Villena-Sax, a Alicante.

(34) Amando MelóN: «El mapa...», pág. 8.

(35) Las tres ciudades, con sus partidos, pasaron de Alicante a Valencia en 1836: cfr. V.c) y $d$ ).

(36) "Aunque se le había segregado de Valencia en las divisiones anteriores», dice el decreto de 1833. 
No reapareció la Provincia de Játiva, repartida en 1833 entre las de Alicante y Valencia, si bien después de los cambios «internos» de 1836 y 1847 la de Valencia vino casi a coincidir con la suma de las Provincias de Valencia y Játiva de 1822-23, mientras que se reducía la Provincia de Alicante a una extensión muy poco más de la mitad de la de Valencia; en cambio, la frontera septentrional de ésta quedó algo más al sur que en 1822, es decir, Castellón resultó mayor que en la división llevada a cabo en dicho año. En el artículo $1 .^{\circ}$ de otro Real Decreto, también de 30 de noviembre de 1833, "para el establecimiento de los subdelegados de Fomento [Gobernadores civiles; se dispuso:] se dividirán las provincias del Reino en tres clases»: Valencia, con otras siete, era de primera; Alicante y otras seis, de segunda; y Castellón y todas las demás, de tercera.

La división de 1822 era no poco deficiente, pero fue aprovechada en cierta medida por la actual, aunque yo ahora sólo quiero señalar (algo más que señalar pienso hacer cuando pueda, Deo volente) la ratificación y consagración del término Provincia, que, a pesar de su bimilenaria y romana estirpe, parece que a algunos casi les pone fuera de sí: sin casi a veces; y para mí, sin razón siempre. Nuestra literatura clásica ha utilizado el término constantemente; y la legislación española ya hablaba de Provincias desde hace varios siglos... y lo mismo la Constitución actual votada en 1978 (37).

(37) Provincia significa en el Derecho español el territorio al que extiende su competencia una autoridad denominada generalmente Gobernador civil (puede verse la argumentación conveniente en el ya citado libro División territorial...), y es, por tanto, también el gobierno, poderes o competencia de una autoridad.

$Y$ así era ya en Roma, como dice Alvaro D'Ors: "Sobre el no-estatismo del Imperio romano», en Atlántida, 19 (1966), 85: «Prouincia, otra idea que refleja también la concepción personalista romana, pues significa propiamente una atribución de competencia personal, y sólo secundariamente la delimitación territorial de la competencia de los magistrados prorrogados para el gobierno fuera de Italia. Y así con todas las estructuras menores que comprende la provincia: municipium en sentido territorial es secundario respecto al sentido personal de conjunto de personas que participan en las cargas comunes, los municipes; colonia como ciudad, secundario respecto a los coloni; conuentus como división judicial, secundario respecto al sentido personal de reunión con ocasión de la visita del gobernador, etc.»

Los primeros gobernadores de las Provincias valencianas (subdelegados principales de fomento se llamaban inicialmente) fueron designados por reales decretos de 10 y 14 de diciembre de 1833, y fueron: de Alicante, Bernardo Borjas Tarrius; de Castellón, José Codina Gómez, y de Valencia, José Galdeano. Francisco Almela y Vives: Valencia y su Reino, Valencia, 1965, 224-25.

Respecto de Galdeano, también Carlos R. Eguía: voz "Valencia», en la $G E R$, volumen XXIII, Madrid, 1975, 206. 


\section{LAS DIVISIONES SUPRA- O INFRAPROVINCIALES EN LA SEGUNDA MITAD DEL XIX}

Esta materia fue objeto ya de varias páginas, con carácter general, en Geografía administrativa de Aragón (38), y no es cuestión de repetir lo dicho allí, adonde me remito ahora globalmente.

Ciñéndonos al caso valenciano, y esquemáticamente, he aquí los distintos proyectos o realizaciones (39).

a) División de la Península en once Gobiernos generales por Real Decreto de 29 de septiembre de 1847, siendo Ministro de la Gobernación Patricio de la Escosura: en su artículo 2..$^{\circ}$ decía: $44 .^{\circ}$ Valencia y Murcia, su capital Valencia. Comprende las provincias de Valencia, Murcia, Alicante, Albacete y Castellón». Otro Decreto de la misma fecha nombraba los Gobernadores generales: de Valencia-Murcia y, por tanto, también Gobernador civil de la Provincia de Valencia, el Mariscal de campo (General de división) don Ramón de Salas. Pero el citado Real Decreto de división supraprovincial fue suspendido, derogado en realidad, por otro de 5 de octubre de 1847, esto es, seis días después, del nuevo Ministro de la Gobernación del Reino, Luis José Sartorius.

b) Real Decreto de 30 de septiembre de 1847: establecía subdelegaciones o distritos civiles, uno o varios en las diversas Provincias, y concretamente tres de tercera clase en la de Alicante: Alcoy, Elche y Orihuela; dos de segunda en la de Castellón: Morella y Vinaroz; y cuatro en la Provincia de Valencia: de primera, en Játiva; de segunda, en Gandía, y de tercera, en Chelva y en Chiva; claro está que esta disposición corrió la misma suerte que la anterior: fue "suspendida" por Sartorius el 5 de octubre.

(38) Conferencia publicada en folleto, sin año, en Zaragoza; y en REvisTa DE Estudios DE LA VIDA LOCAL, 200 (1978), 737-60.

(39) Pero ya antes se había publicado el siguiente decreto: «El Gobierno provisional no podía menos de tributar una prueba inequívoca del aprecio á que se ha hecho acreedora la ciudad de Valencia en el último alzamiento nacional. Deteniendo con un arrojo denodado la marcha del ex-Regente, y sin perderlo de vista, se desprendieron los. valencianos de sus principales fuerzas: las enviaron en socorro de Teruel, y las vieron llegar victoriosas hasta las puertas de la corte, dando un golpe de muerte á los que se oponían al voto de los pueblos. Tan distinguidos hechos merecen bien de la patria, y que sean conocidos de la posteridad en los timbres de los ciudadanos esforzados.

Por tanto, en nombre de S. M. la Reina Doña Isabel II, ha venido en decretar:

Artículo 1. La ciudad de Valencia añadirá á sus anteriores dictados el de Magnánima.

Artículo 2. En derredor del escudo de sus armas pondrá diez y seis banderas desplegadas.

Dado en Madrid á 19 de agosto de 1843.-Joaquín María López, Presidente.-El Ministro de la Gobernación de la Península, Fermín Caballero».

Confieso desconocer la suerte y ejecución del texto transcrito. 
c) El propio Sartorius, con su Real Decreto de 1 de diciembre del mismo 1847, resucitaba los distritos y, entre ellos, los siguientes: de primera clase, Játiva (Valencia), que comprendía también los distritos electorales de Gandía y Onteniente; de segunda, Alcoy (Alicante), que abarcaba además el distrito de Pego; también de segunda, Requena (Cuenca, entonces), que se extendía a Motilla del Palancar; y de tercera, Segorve (sic: Castellón), que incluía asimismo el distrito electoral de Nules. Los jefes de distrito se llamaron jefes civiles por Real Orden de 6 de enero de 1848, pero fueron suprimidos por Real Decreto, también firmado por Sartorius, de 19 de septiembre de 1849.

d) Efímera fue la vida de los Decretos reseñados en los tres párrafos anteriores, pero otros dos proyectos de división "regional» quedaron en estado de concebidos y no nacidos, no llegaron a asomarse en la Gaceta de Madrid: el de Segismundo Moret, de 6 de enero de 1884, preveía quince «Regiones» (no: superprovincias): una de ellas era la de Valencia, Castellón, Cuenca y Teruel; y otra, la de Murcia, Albacete y Alicante: se comprende que abortara; y el proyecto de Sánchez de Toca (1891, trece "Regiones»), que hacía una Región con las tres Provincias valencianas, más Albacete y Murcia (40).

e) Un último y doble tema queda por tratar, el de los Partidos judiciales y las Comarcas pero, en mi opinión, merece más atención de la que puedo dedicarle ahora, por lo que habrá de esperar coyuntura más propicia... que procuraré se presente.

\section{VALENCIA, CAPITAL DE «REGIONES» ADMINISTRATIVAS ESPECIALES}

Por supuesto, Valencia, que ha sido siempre capital del Reino al que dio nombre, lo es de la Entidad preautonómica y está previsto que lo sea de la Comunidad autónoma, según el artículo $6 .^{\circ}$ del proyecto de Estatuto: "La sede de la Generalidad valenciana (41) radi-

(40) Ya se ve que esos proyectos no tenían en gran consideración la historia, más viva de lo que pensaban: en 1982, y camino de convertirse en Comunidades autóno mas, las Entidades preautonómicas se reparten así las provincias citadas en el texto: Valencia comprende exactamente sus tres provincias; Murcia, sola; Albacete y Cuenca se integran en Castilla-LaMancha; y Teruel, en su sitio, en Aragón.

(41) Artículo 9. "1. El conjunto de las instituciones de autogobierno de la Comunidad constituye la Generalidad Valenciana.

2. Forman parte de la Generalidad: las Cortes Valencianas o Corts, el Presidente, el Gobierno valenciano o Consell y las demás instituciones que determine el presente Estatuto». 
cará en el Palacio de su nombre, sito en la ciudad de Valencia. Sus instituciones podrán establecerse y celebrar reuniones en cualquiera de los Municipios de la Comunidad, de acuerdo con lo que determine la ley».

Pero Valencia es también capital regional de diversos servicios estatales, sin más excepciones, al menos de importancia externa, que los marítimos y los aéreos militares.

a) En primer lugar, coinciden con el territorio valenciano: la Audiencia territorial (art. 41 de la Ley provisional orgánica del Poder Judicial de 15 de septiembre de 1870); y la Delegación regional de Comercio (Decreto de 30 de agosto de 1974), con centros de inspección del comercio exterior en Castellón, Valencia, Gandía y Alicante (Orden de 16 de febrero de 1979).

Así fue también el Distrito universitario de Valencia desde que por Real Orden de 23 de marzo de 1915 se creó la Universidad de Murcia, hasta que por Ley de 30 de octubre de 1979 se creó la de Alicante: el Distrito de ésta es la Provincia del mismo nombre; el de la Universidad de Valencia comprende ahora esta Provincia y la de Castellón (42); también comprendía las tres Provincias valencianas la efímera y no estrenada Delegación territorial del fugaz Ministerio de Planificación del Desarrollo, pues creadas por Decreto de 16 de noviembre de 1973, las Delegaciones fueron suprimidas, sin que llegaran a funcionar, por el de 8 de abril de 1976; a efectos de su representación en el Tribunal de Garantías Constitucionales (artículo 11.2 de la Ley de 14 de junio de 1933), entre las Regiones se contaba la de "Valencia (Provincias de Alicante, Castellón y Valencia)».

Y así aparece también, con esa denominación, al enumerar las «Regiones españolas» el acuerdo hispano-suizo sobre protección de indicaciones de procedencia, denominaciones de origen y otras similares, publicado en el BOE de 17 de marzo de 1976.

b) Un segundo grupo puede hacerse con las circunscripciones que con sede en Valencia extienden su competencia fuera de las tres Provincias: es el caso, en primer lugar, de la Delegación especial de Hacienda de Valencia, que comprende, además, las Delegaciones de

(42) Aurelio Guaita: El distrito universitario, Madrid, 1967.

Por Orden de 7 de junio de 1938 se dispuso: «El territorio correspondiente a los distritos universitarios de Barcelona y Valencia, a medida que se vaya logrando su liberación, quedará agregado provisionalmente para todos los efectos y hasta nuevo acuerdo al de Zaragoza»; no lo he visto publicado, pero sin duda se debió de adoptar dicho acuerdo. 
Murcia y Cartagena (43); también comprende a la Provincia de Murcia la VII División regional agraria: Orden de 8 de junio de 1972; y lo mismo acontecía con la Jefatura Regional de Costas y Puertos: Decreto del Ministerio de Obras Públicas de 17 de abril de 1975, pero las Jefaturas de Costas fueron suprimidas por Real Decreto de 16 de noviembre de 1979.

Comprenden las Provincias de Valencia, Alicante, Castellón, Murcia y Albacete: la III Región militar (Decreto de 11 de febrero de 1960); la Jefatura Superior de Policía (art. 77 del Reglamento Orgánico de la Policía gubernativa de 17 de julio de 1975 y Orden de 6 de diciembre de 1976); la III Circunscripción de la Policía Nacional (Orden de 13 de diciembre de 1979) (44), y la VI Inspección Regional de Obras Públicas (Decreto de 17 de abril de 1975). Esas mismas cinco Provincias comprendía inicialmente el Distrito universitario de Valencia desde su creación en el artículo $80^{\circ}$ del Reglamento del "plan de estudios" de 23 de octubre de 1845, ratificado por el 259 de la Ley general de Instrucción Pública o "Ley Moyano" de 9 de septiembre de 1857, hasta que se estableció la Universidad de Murcia en 1915, que formó su Distrito con esta Provincia y la de Albacete; y también abarcaban las cinco Provincias el efímero Gobierno general establecido por Escosura y una de las "Regiones» previstas en el proyecto de Sánchez de Toca, como ya queda dicho.

A esas cinco Provincias agregaba la de Cuenca el Jurado Tributario territorial: Orden de 31 de julio de 1964; pero los Jurados fueron suprimidos por la Ley de Reforma del Procedimiento tributario de 21 de junio de 1980.

Por su parte, la Región aérea de Levante añadía una séptima Provincia, Teruel, a las seis anteriores: Valencia, Castellón, Alicante, Albacete, Murcia y Cuenca: Decreto de 17 de octubre de 1940; pero esa Región (como la llamada Atlántica: Valladolid) fue suprimida por Decreto de 1 de febrero de 1968: en esa reorganización las Pro-

(43) Orden de 27 de abril de 1979.

Además existen administraciones de Hacienda en las siguientes poblaciones valencianas: Gandía (Orden de 25 de abril de 1979: comprende también la zona de recaudación de Onteniente); Alcoy, Elche, Elda (con Villena), Valencia-Norte (con Liria y Sagunto), Valencia-Sur (con Carlet y Sueca), Játiva (con Alcira y Enguera) y Requena (con Ayora): Orden de 14 de noviembre de 1979.

(44) Según la Orden de 17 de octubre de 1979 existen comisarías locales de policía en Alcoy, Benidorm, Denia, Elche, Elda-Petrel, Orihuela, Villajoyosa y Villena; Burriana, Vall de Uxó y Villarreal de los Infantes; y Alcira-Algemesí-Carcagente, Burjasot, Gandía, Játiva, Mislata, Onteniente, Paterna, Quart de Poblet-Chírivella-Manises, Sagunto, Sueca; y Torrent-Alaquás. 
vincias de Valencia y Castellón pasaron a la III Región aérea (Zaragoza), y la de Alicante, a la II (Sevilla) (45).

También cuenta siete Provincias, pero sustituyendo Cuenca por Baleares, la III Zona de la Guardia civil y la IV Jefatura Regional de Tráfico: Valencia, Castellón, Alicante, Teruel, Albacete, Murcia y Baleares: Ordenes de 28 de diciembre de 1974 (BOGC, enero de 1975) y 5 de marzo de 1975.

c) La división marítima merece párrafo aparte: las Provincias valencianas marítimas coinciden exactamente con las civiles (caso, por cierto, muy poco frecuente) y pertenecen a la Zona marítima del Mediterráneo (Cartagena); Alicante es la capital de la Región de pesca de Levante (desde el Cabo de Gata, en Almería, hasta el límite con Valencia), mientras que Valencia y Castellón pertenecen a la Región de pesca de Tramontana (Barcelona) (46).

d) Singular es también por fuerza la división natural en Comisarias de aguas, coincidentes con las Confederaciones hidrográficas (Decreto ya citado de 17 de abril de 1975): la casi totalidad del territorio valenciano y buena parte de las Provincias de Teruel, Cuenca y Albacete, y hasta una porción diminuta de Tarragona, entran en la Confederación del Júcar (47), con capitalidad en Valencia; en cambio, el ángulo noroeste (Morella) vierte sus aguas al Ebro (Zaragoza), y el extremo meridional (Orihuela, Guardamar, etc.) lo surca el Segura (Murcia).

e) Para terminar este breve catálogo en torno a la capitalidad valenciana puede aludirse a la división eclesiástica, pues al fin y al

(45) Murcia-Alicante, con sede en aquélla, forman un sector aéreo en la segunda región; y Valencia-Castellón-Teruel, uno en la tercera: Ordenes de 26 de noviembre de 1981 y 16 de febrero de 1968, respectivamente.

Se puede recordar que el ya citado y peregrino proyecto de Moret de 1884 hacía, entre otras, estas dos «regiones»: Valencia-Castellón-Teruel-Cuenca, y Murcia-AlbaceteAlicante.

(46) De sur a norte los distritos marítimos valencianos son los siguientes: Torrevieja, Santa Pola, Alicante, Villajoyosa, Benidorm, Altea, Denia; Gandía, Valencia, Sagunto; Burriana, Castellón y Vinaroz: Reales Decretos de 14 de diciembre de 1973 y 3 de mayo de 1977.

(47) Este es el río más importante y el que da nombre a la confederación hidrográfica y a la comisaría, pero una y otra comprenden todos los ríos que vierten al Mediterráneo entre el Ebro y el Segura; entre ellos destaca el Turia, con su renombrado Tribunal de les Aigües.

Sobre éste puede verse el "Tratado de la distribución de las aguas del río Turia, y del Tribunal de los Acequieros de la Huerta de Valencia, por don Francisco Xavier Borrull y Vilanova, del Consejo de S. M., Oidor de la Real Audiencia de este Reino, é individuo honorario de las Reales Academias de San Fernando, de San Carlos, de San Luis y de la Sociedad Económica de su Patria. Valencia: Ymprenta de D. Benito Monfort, diciembre $1831 »$. 
cabo, tiene algunos efectos en el derecho estatal, secular o civil: son hoy sufragáneas de la Sede metropolitana valentina las Diócesis de Segorbe-Castellón, Orihuela-Alicante, Mallorca, Menorca, Ibiza y Albacete; el norte de la Provincia de Castellón (Morella, San Mateo, Vinaroz, Benicarló, Peñíscola...) sigue siendo Diócesis de Tortosa.

\section{APENDICE: «LA DENOMINACION QUE MEJOR CORRESPONDA A SU IDENTIDAD HISTORICA»}

Aprobado ya por el Congreso de los Diputados (28 de abril de 1982) el proyecto de Estatuto de Autonomía de Valencia (aunque con distinto nombre, cuya vigencia efectiva se puede vislumbrar con justificado escepticismo), me parece oportuno reproducir el artículo que «en tiempo y forma» publiqué en la prensa (48) con el título "Vocamus et volumus ut Regnum Valentie appelletur», y que decía y dice así:

«Así comienzan, exactamente con esas palabras y grafía, els Furs valencianos, cuyas disposiciones más antiguas, como la que ampara estas líneas (libro I, rúbrica I, fur 1: Jacobus I - Rex) datan ya de la primera mitad del siglo XIII, a pocos años de la conquista.

Don Jaime estaba doblemente legitimado para iniciar la ley fundamental de su nuevo reino con tan categóricas palabras, «lo llamamos y queremos que se llame Reino de Valencia», porque él mismo se injertaba en la Historia sin hacer ninguna cesura en ella (cuántas veces dijo y ordenó: «¡Com en temps dels sarraïns!»): conquistó el reino de Valencia, más que unas tierras, y reino de Valencia quedó, pero no se limitó a sobreponerse als sarraïns, pues real y verdaderamente creó un reino de Valencia nuevo: furs propios, conversión de la mezquita en catedral de Santa María, inserción de Valencia en la Corona de Aragón junto a los reinos de Aragón y Mallorca y al condado de Barcelona. Pero su nuevo reino no lo obtuvo por herencia o matrimonio, sino por su valor y la fuerza de su brazo: fue una creación suya, una criatura suya, y tenía indiscutible derecho para nominarla (aquí sí está bien empleada esta palabra).

Cavanilles, a fines del xvirr, es decir, casi un siglo después de Almansa, seguía hablando de reino de Valencia. Denominación indiscutible e indiscutida durante siete siglos, hasta que el furor his-

(48) «ABC» de Madrid del 26 de enero de 1982; reproducido por los peri6dicos valencianos «Murta» (enero) y «Levante» (21 de marzo de 1982). 
toricida de quienes hablan de nacionalidades históricas, queriendo sin duda emular a los que gustan de cambiar nombres de calles y queriendo no ser menos que algunos países recién llegados a la civilización, a la independencia o a la conciencia de su identidad (el tercer mundo está lleno de ejemplos de estos países rebautizados), deciden que Valencia se llame «país».

Donoso descubrimiento éste. Claro que Valencia es un país: como Italia, como Francia, como Extremadura; pero tiene su nombre propio, que no es "País Valenciano", sino Valencia; como sería estrafalario hablar de país italiano, país francés, país extremeño. La más elemental gramática enseña el significado y el uso correcto de los adjetivos y de los nombres o sustantivos; aquéllos derivan de éstos, no existen sin éstos, pero son éstos los que han de emplearse para nombrar cosas y personas porque indican su identidad y sustancia. Quienes a todo trance desean evitar el nombre (Valencia; prefieren decir País Valenciano) recuerdan por fuerza - a veces quizá sean los mismos- a quienes emplean grotescos circunloquios y perífrasis para no decir España: «el Estado español», «en todo el territorio del Estado" y otras lindezas semejantes. Por ejemplo hace poco ha llovido "en casi todo el territorio del Estado" ( sic). Hay otras "razones» para hablar de país: una, que así se afirma la sustantividad de Valencia frente a la de España: son dos países interajenos, no aquél parte de éste. No es para describir la tristeza y vergüenza que sentí hace unos días al leer esta "pintada" en aquella ciudad: "¿España? No, gracias». Se comprende que tampoco quieran ni escuchar el himno de Valencia, de los valencianos Serrano y Thous, que comienza: «Para ofrendar nuevas glorias a España». Y una segunda razón (?) es que "país" sintoniza mejor con la idea de la España pequeñita que algunos llaman "països catalans».

Tampoco sería de recibo la más reciente invención propuesta por algunos, la inelegante y aséptica denominación de «Comunidad Autónoma Valenciana»: un peregrino pero lógico paralelo sería, por ejemplo, "Nacionalidad Independiente Española» en vez de decir España. Cualquier apelativo que prescinda del nombre propio - Valencia, no hay otro- es burdo sucedáneo y como tal ha de rechazarse de plano.

Ni la Historia ni la gramática concuerdan con eso del "país". Tampoco la legislación: desde el vigente real decreto de la división provincial de 30 de noviembre de 1833, que habla de reino de Valencia, hasta el artículo 147.2 de la Constitución, que dispone 
(no aconseja, permite o tolera) que «los Estatutos de Autonomía deberán contener: a) La denominación de la Comunidad que mejor corresponda a su identidad histórica», y no hace falta apelar a Menéndez Pidal o a Sánchez Albornoz para detectar infaliblemente la denominación que identifica históricamente a Valencia.

Más: está previsto en el artículo 52.2 de la Constitución que el Rey de España puede también «utilizar los demás (títulos) que correspondan a la Corona»; y lo corrobora la práctica acerca de dos títulos concretos y menores, pero propios del Soberano español: el Condado de Barcelona y el Señorio de Vizcaya, denominación ésta no sólo histórica, sino también vigente y rehabilitada por el real decreto de 4 de marzo de 1977. Otro ejemplo: el reciente Estatuto de Asturias dice en su artículo $10^{\circ}$ que esa comunidad autónoma "se denomina "Principado" de Asturias".

Reino de Valencia es, como se acaba de decir y de ver, la denominación exacta y cabal; pero si la alergia histórico-monárquica de algunos les obceca hasta la más empecinada intransigencia, por mi parte no habría inconveniente en silenciar lo de reino, concediendo que al fin y al cabo es una calificación histórica y jurídico-constitucional, adjetiva, por tanto, frente al sustantivo Valencia, éste sí absolutamente irrenunciable.

¿Que habría homonimia de ciudad y comunidad autónoma? ¡Es que la hay! Siempre ha sido así: "la Ciutat y Regne de Valencia"; fue y es aquélla la que dio y da nombre a éste. Y tampoco tiene mayor importancia esa anfibología, que al fin y al cabo ocurría también en León y en Murcia y acaece hoy en la casi totalidad de las provincias españolas y en unos cuantos países pequeños o grandes de tres continentes: Andorra o Luxemburgo, Túnez (no acaba de popularizarse Tunicia), Panamá, Guatemala y, ejemplo cimero, México. Pues eso es precisamente lo que puede leerse en el Acuerdo hispano-suizo sobre protección de indicaciones de procedencia y denominaciones de origen («BOE» de 17 de marzo de 1976) al nombrar la totalidad de las regionés españolas, y es eso también lo que hace el acuerdo $2 / 1981$, de 16 de septiembre ( BOE» del 10 de noviembre), sobre criterios de distribución del Fondo de Compensación Interterritorial, en cuya relación de comunidades autónomas y entidades preautonómicas figura la nuestra com Deu mana: VALENCIA». 